\title{
Optimize of LIBS Setup to the Determination of Laser Breakdown Power of Writing Inks
}

\author{
Hussam S. Sadam ${ }^{1 *}$, Sami A. Habana ${ }^{1 *}$, Alaa H. Ali ${ }^{2}$ \\ 1. Department of Laser Physics/ College of Science for Women / University of Babylon, Baghdad, Iraq. \\ 2. Department of Materials Research / Ministry of Science and Technology, Baghdad, Iraq. \\ *E-mail of the corresponding author: hussamsadoon90@gmail.com
}

\begin{abstract}
Laser-induced breakdown spectroscopy system (LIBS) had been designed to the determinate of the best ionization laser power for analysis of the writing inks via analysis induced plasma emission. Passively QSwitched Nd:YAG laser at the fundamental wavelength $1064 \mathrm{~nm}$ with different energies $(60 \mathrm{~mJ}, 80 \mathrm{~mJ}, 100 \mathrm{~mJ}$, $200 \mathrm{~mJ}, 300 \mathrm{~mJ}, 400 \mathrm{~mJ}$ and $500 \mathrm{~mJ})$ with $(10 \mathrm{~ns})$ pulse duration, the laser beam was focused via converging lens with focal length $(100 \mathrm{~mm})$ that generates different power intensity, optical spectrum analysis system used was within (Si-CCD) array detector, within spectrum range of $(200-900 \mathrm{~nm})$ with $(0.8 \mathrm{~nm})$ optical resolution. Use A4 sheets of commercially available standard white office paper with 2 Ballpoint pens and 1 Gel pen as samples. Show the results that the laser energy $(80 \mathrm{~mJ})$ with $\left(2.66 \times 10^{12} \mathrm{~W} / \mathrm{cm}^{2}\right)$ power density, was the best power to generate plasma homogeneous for all component writing inks and ionize it without effect on the paper material. Keywords: LIBS, Laser intensity, Writing inks, White paper, plasma emissions lines, emission line analyses DOI: $10.7176 / \mathrm{CPER} / 61-05$
\end{abstract}

Publication date: July $31^{\text {st }} 2019$

\section{Introduction}

The laser-induced breakdown spectrometry technique (LIBS), in which a short laser pulse is focused onto a sample surface to generate the plasma, the target can be solid, or liquid, or gas. Then, transporting a large amount of energy to the target, begin temperatures to rise, melts, evaporates, and ionization of materials on the surface, this leads to the formation of hot small plasma. Due to the high intensive energy, that increases the temperatures in the target.

The plasma begins to expand and formed by an ionized gas, during the period of time excited atoms begins to relax back to ground level, and then light-emitting unique called plasma spectrum emissions. Because of all elements of the periodic table has a spectral fingerprint especially that can be distinct from the other materials (Miziolek 2006).

In recent years, there have been major developments in LIBS. Thus, LIBS fulfills the basic requirements of questioned document examinations: firstly, simultaneous multi-elemental analysis of inks can be performed directly on paper without any preparation of samples, and secondly, the LIBS a semi-destructive technique. Because The surface area interrogated by the laser pulse involves a very small amount of tested material. This technique tremendous achievements in laser technology and reagents has achieved, that later became the effective techniques for the analysis of colorants in works of art, illuminated manuscripts and archaeological remains (Oujja 2005, Ponterio, 2008, Mateo 2009, Melessanaki 2001).

The LIBS technique has also been employed to study binders and pigments present in paper (Häkkänen 1998). As well as, the possibilities of LIBS in the analysis of contemporary writing inks (Trejos 2010, El-Deftar 2014, Hoehse 2012). In these procedures, LIBS was only a supplementary technique to laser ablation inductively coupled plasma mass spectrometry (LA-ICP-MS) or Raman spectroscopy (RS). Moreover, examinations were only conducted for a limited number of inks, eleven black gel inks, and ten black and blue inks, respectively. With the use of emission lines of only 4 elements, Trejos et. al. were successful in discrimination of $96.4 \%$ of all possible pairs of samples. M. El-Defter concluded the presence of $\mathrm{Al}, \mathrm{Ca}, \mathrm{Mg}, \mathrm{Mn}, \mathrm{Na}, \mathrm{Sr}$, and $\mathrm{Ti}$ in analyzed office Paper and $\mathrm{Al}, \mathrm{Ca}, \mathrm{Cu}, \mathrm{Mg}, \mathrm{Na}, \mathrm{Si}$, Ti in analyzed Ballpoint Inks of these matrices by LIBS. On the other hand, Hoehse et al. concluded that revealing the presence of $\mathrm{Cu}, \mathrm{Ti}, \mathrm{K}, \mathrm{Ca}, \mathrm{Na}, \mathrm{Li}$, and $\mathrm{Al}$ in analyzed inks was insufficient to discriminate the sample set when separate LIBS data. Therefore, these investigations showed the potential of utilizing the LIBS method in the field of document examinations for forensic purposes.

The forensic evidence types are documents including office papers, writing inks, inkjet inks, and laser printer toners. A comparison analysis seeks to determine if two samples have a common origin. When two or more samples can be said to have originated from the same source with confidence, then the evidence is said to possess individual characteristics. In spite of the modern world of computers, scanners, and printers, the number 
of handwritten documents has been drastically reduced. However, handwritten notes, such as signature is still required as proof of consent in many cases, such as altered wills and a prescriptions labels, business and personal cheques, traveler's cheques and medical records continue to be widely used by people (Kula 2014).

\section{Materials and methods}

\subsection{Samples}

Three samples of writing pens, 2 blue and 1 black writing pens of various types ( 2 ballpoint pens and 1 gel pens) produced by different manufacturers as shown in table (1). The ink depositions on white office paper were made in the form of straight lines, applying normal hand pressure.

Table 1. List of pens examined in the study.

\begin{tabular}{|c|c|c|c|c|c|}
\hline No. & Type of pen & Color & Brand & Manufacture & Sample symbol \\
\hline 1 & Ballpoint pen & Blue & Cello & Germany & BB1 \\
\hline 2 & Ballpoint pen & Black & Lexi & India & BK2 \\
\hline 3 & Gel pen & Blue & Uniball & Japan \\
\hline
\end{tabular}

2.2. Experimental setup

A LIBS system as shown in Figure (1).

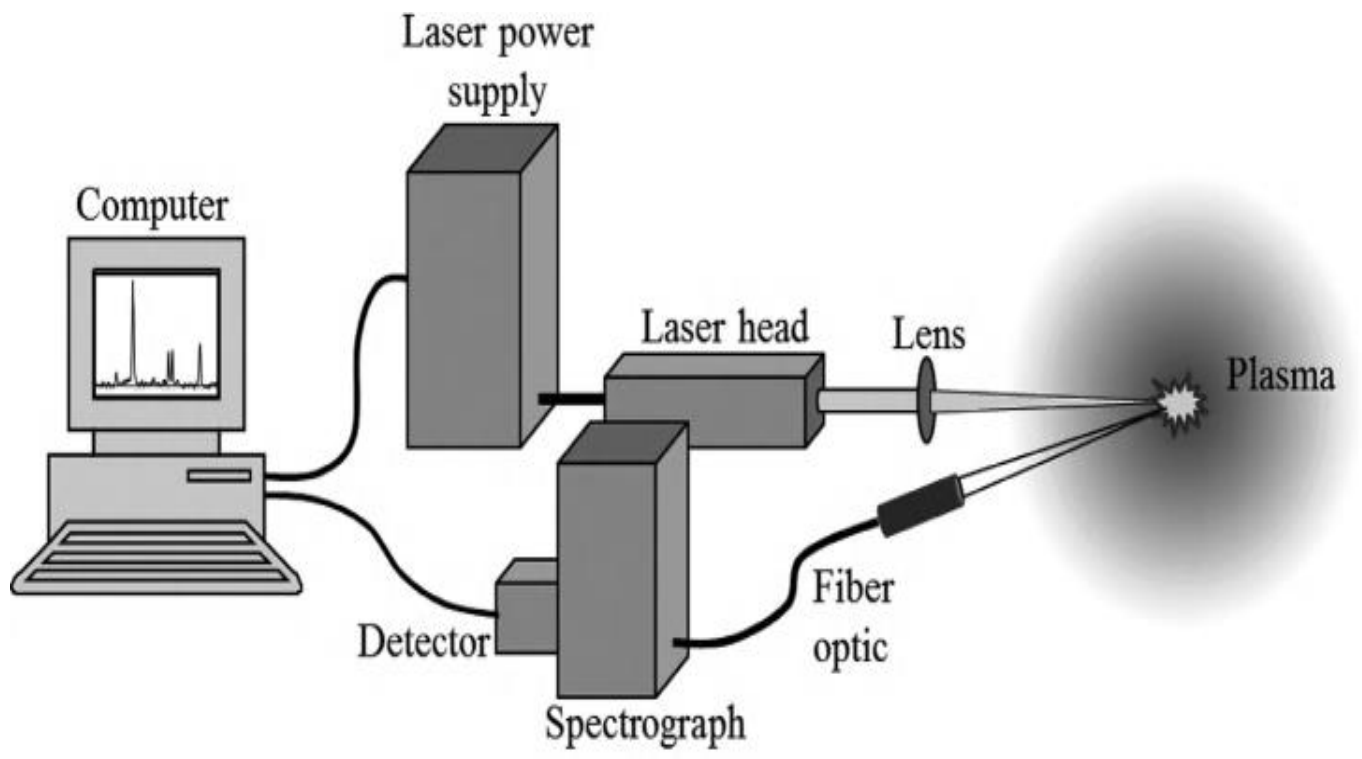

Figure 1. Schematic diagram of LIBS experimental setup.

was designed to detect the optical emission spectra for plasma ablation from writing inks in air. The system consists of Q-switching Nd-YAG laser operated at the fundamental wavelength of (1064 nm) with a pulse duration of (10 ns), was used for plasma generation. Different energies $(60,80,100,200,300,400$ and 500$) \mathrm{mJ}$ were used. The laser beam was focused onto the sample by a converging lens from the fundamental diameter $(5 \mathrm{~mm})$ to become $(0.02 \mathrm{~mm})$ on a sample, with a focal length of $(100 \mathrm{~mm})$. The sample had placed in the sample holder in the ambient atmosphere. The distance between the focusing lens and the sample was (100 mm), kept less than the focal length of the lens for the prevention of any breakdown of the ambient air in front of the target. Optical fibre adjusted at $45^{\circ}$ angle with a beam direction directed at $(50 \mathrm{~mm})$ distance from the sample. plasma emission collected by a collimator lens, which is designed to connect to the end of optical fibres of SMA905 connector and contains an AR-coated aspherical lens, which is used to collimate the beam out of fibre, and focused onto optical fibre diameter $(200 \mu \mathrm{m} / 0.22 \mathrm{NA})$, which deliver the plasma emission to the entrance slit of an inside spectrum analyser (type Spectra View 2100) with sensor from silicon charge coupled device (Si-CCD) array that consists of an array of detectors to record the spectral lines with (600 Lines $/ \mathrm{mm})$ grating, Which serves to deflect light according to wavelength and then reversed by mirrors to detect and convert optical signals to digital as show in figure (2), and then moves the digital signal to the application Visual Spectra 2.1 program to record the spectrum in PC-computer to shows the spectral lines for the materials and then be analysed. The spectrum was recorded over a (200-900) $\mathrm{nm}$ wavelength range with resolution $(0.8 \mathrm{~nm}) \mathrm{FWHM}$ and time integration $(500 \mathrm{~ms})$ using a spectrum analyser. All spectral data have been identified from the National Institute of Standards and Technology (NIST) database (Sansonetti 2005, Karamida 2018). 


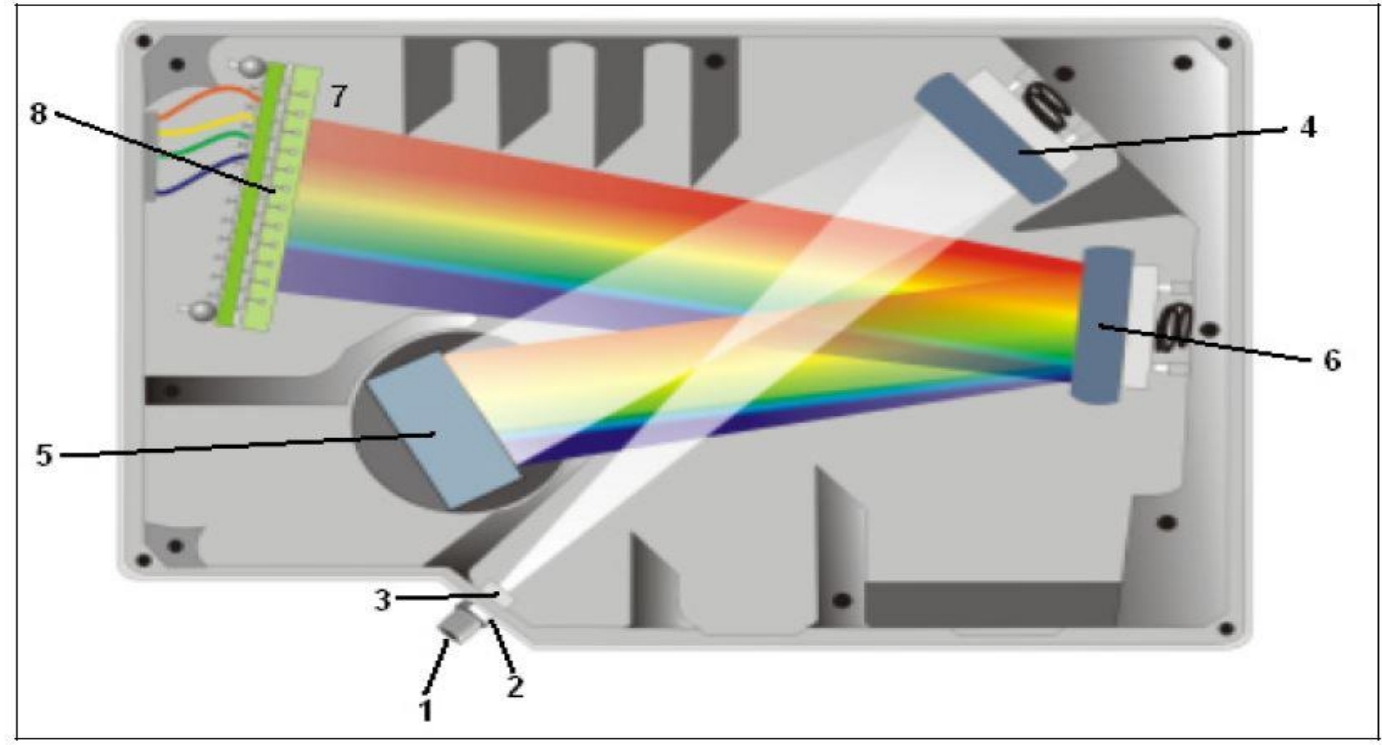

Figure 2. Internal design diagram of optical spectrum analyser.

Where

1- SMA 905 connector

2- Fixed entrance slit $(50 \mu \mathrm{m})$

3- Long pass absorbance filter

4- Collimating mirror

5- Grating and wavelength range

6- Focusing mirror

7- L2 and L4 detector collection lenses

8- Detector

\subsection{Checking of the system}

The pure metal of Iron $(\mathrm{Fe})$ and Lead $(\mathrm{Pb})(99,99 \%)$ was used as a calibration samples to determine the emission spectrum lines emitted from these materials, and compare them with the emission lines of standard spectra maintained at NIST. Thus, the investigation of the setup system LIBS and give trust for this technique.

\section{Measuring of laser beam diameter of the target}

The Nd:YAG pulsed laser was used with $(1064 \mathrm{~nm})$ to generate plasma, the beam diameter of the laser $(5 \mathrm{~mm})$ was focused using a lens with $(100 \mathrm{~mm})$ focal length. the laser spot size at the target surface can been measure used

the following equation.

$$
\text { Spot Diameter }\left(\mathrm{d}_{\mathrm{o}}\right)=\frac{\text { 1.27.f.wavelength. }\left(\mathrm{M}^{2}\right)}{\mathrm{D}}
$$

where $\mathrm{f}$ is the focal length of the focus lens, $\mathrm{D}$ is the diameter of the laser beam at the lens, and $\mathrm{M}$ is the beam quality. A factor $M^{2}$ is used to describe the deviation of a beam from a theoretical Gaussian. This is called the M-squared factor. Theoretically $M^{2}=1$ in a true Gaussian beam (Silfvast 2004, Bass 1994).

Where

$$
\text { Spot Diameter } \begin{aligned}
\left(\mathrm{d}_{\mathrm{o}}\right) & =\frac{1.27 * 100 \mathrm{~mm} * 1064 \mathrm{~nm} * 1}{5 \mathrm{~mm}} \\
& =0.02 \mathrm{~mm}
\end{aligned}
$$

The spot size radius $(\mathrm{r})=0.01 \mathrm{~mm}$

A lens with the focal length $100 \mathrm{~mm}$ is to focus the beam laser and decrease the spot size on the target, which leads to an increase in the power density of the laser. As a result, the creating of the ionization process will be easier and fast.

\section{Power density calculation}

In order to calculate the intensity of the laser, the Nd: YAG pulsed laser with $(1064 \mathrm{~nm})$ was applied with $(60,80$, $100,200,300,400$ and 500) $\mathrm{mJ}$ the pulse laser energy during (10ns) pulse duration on the target to generate plasma. Afterward, the beam diameter of the laser $(5 \mathrm{~mm})$ was focused using a lens with $(100 \mathrm{~mm})$ focal length 
and $(0.01 \mathrm{~mm})$ the spot size radius. As shown in the equations $(2,3,4)$ below (Silfvast 2004, Bass 1994). The first calculation the peak power $(\mathrm{P})$, which can be determined by divided the laser energy $(60 \mathrm{~mJ})$ on the pulse duration $(10 \mathrm{~ns})$ as shown in the equation below.

$$
P(w)=\frac{\mathrm{E}}{\mathrm{tp}}=\frac{0.06 \mathrm{~J}}{10 \times 10^{-9} \mathrm{sec}}=6 \mathrm{MW}
$$

Then, calculate $\mathrm{A}$ is the spot size (the area of the pulsed laser on target) which will be measured as follows:

Where $(\mathrm{r})$ is the spot size radius $(0.01 \mathrm{~mm})$

$$
\text { area of laser } \operatorname{spot}(A) \mathrm{cm}^{2}=r^{2} \times \pi
$$

$$
\begin{aligned}
\mathrm{A} & =0.01^{2} \mathrm{~mm}^{2} \times 3.14 \\
& =3 \times 10^{-6} \mathrm{~cm}^{2}
\end{aligned}
$$

And finally, from equation (4) below, calculate the power density for pulse energy $60 \mathrm{~mJ}$

$$
\begin{aligned}
\text { Power density (irradiance }(I)) & =\frac{P}{A} \\
& =\frac{6 \mathrm{MW}}{3 \times 10^{-6} \mathrm{~cm}^{2}} \\
& =2 \times 10^{12} \mathrm{~W} / \mathrm{cm}^{2}
\end{aligned}
$$

The table (2) below describes the peak power and energy density for different energy.

Table 2. The peak power and energy density for different energy.

\begin{tabular}{|c|c|c|c|}
\hline No. & Laser energy & Peak power & Power density \\
\hline 1 & $60 \mathrm{~mJ}$ & $6 \mathrm{MW}$ & $2 \times 10^{12} \mathrm{~W} / \mathrm{cm}^{2}$ \\
\hline 2 & $80 \mathrm{~mJ}$ & $8 \mathrm{MW}$ & $2.66 \times 10^{12} \mathrm{~W} / \mathrm{cm}^{2}$ \\
\hline 3 & $100 \mathrm{~mJ}$ & $10 \mathrm{MW}$ & $3.33 \times 10^{12} \mathrm{~W} / \mathrm{cm}^{2}$ \\
\hline 4 & $200 \mathrm{~mJ}$ & $20 \mathrm{MW}$ & $6.66 \times 10^{12} \mathrm{~W} / \mathrm{cm}^{2}$ \\
\hline 5 & $300 \mathrm{~mJ}$ & $30 \mathrm{MW}$ & $10 \times 10^{12} \mathrm{~W} / \mathrm{cm}^{2}$ \\
\hline 6 & $400 \mathrm{~mJ}$ & $40 \mathrm{MW}$ & $13.33 \times 10^{12} \mathrm{~W} / \mathrm{cm}^{2}$ \\
\hline 7 & $500 \mathrm{~mJ}$ & $50 \mathrm{MW}$ & $16.66 \times 10^{912} \mathrm{~W} / \mathrm{cm}^{2}$ \\
\hline
\end{tabular}

\section{Results and discussion}

Optimization of the developed method to the determination of ionization laser power density was performed using writing inks applied directly on paper. The aim was known the ionization laser power density for writing inks to obtain a reasonable signal intensity for the elements originating from components of writing inks and without signal intensity for the elements originating from paper.

In this study, white paper with three samples from writing inks as shown in table (1) at different energies was used. The resulted spectral emission lines for elements, were analyzed and compared with the National Institute of Standards and Technology (NIST)spectral database in wavelength ranges $\pm 0.05 \mathrm{~nm}$.

\subsection{The ionization power density for paper}

The emission spectrum of white paper at power density $\left(2 \times 10^{12} \mathrm{~W} / \mathrm{cm}^{2}\right)$, which equates the energy $(60 \mathrm{~mJ})$ from laser energy was recorded by spectrum analyzer. The intensity of emission spectral lines of generated plasma has its power density, as shown in fig. (3). The analysis is made using the emission wavelength $(\lambda)$ and intensity(I) of the emission line. The resulted spectral emission lines for elements are show in the table (3). 


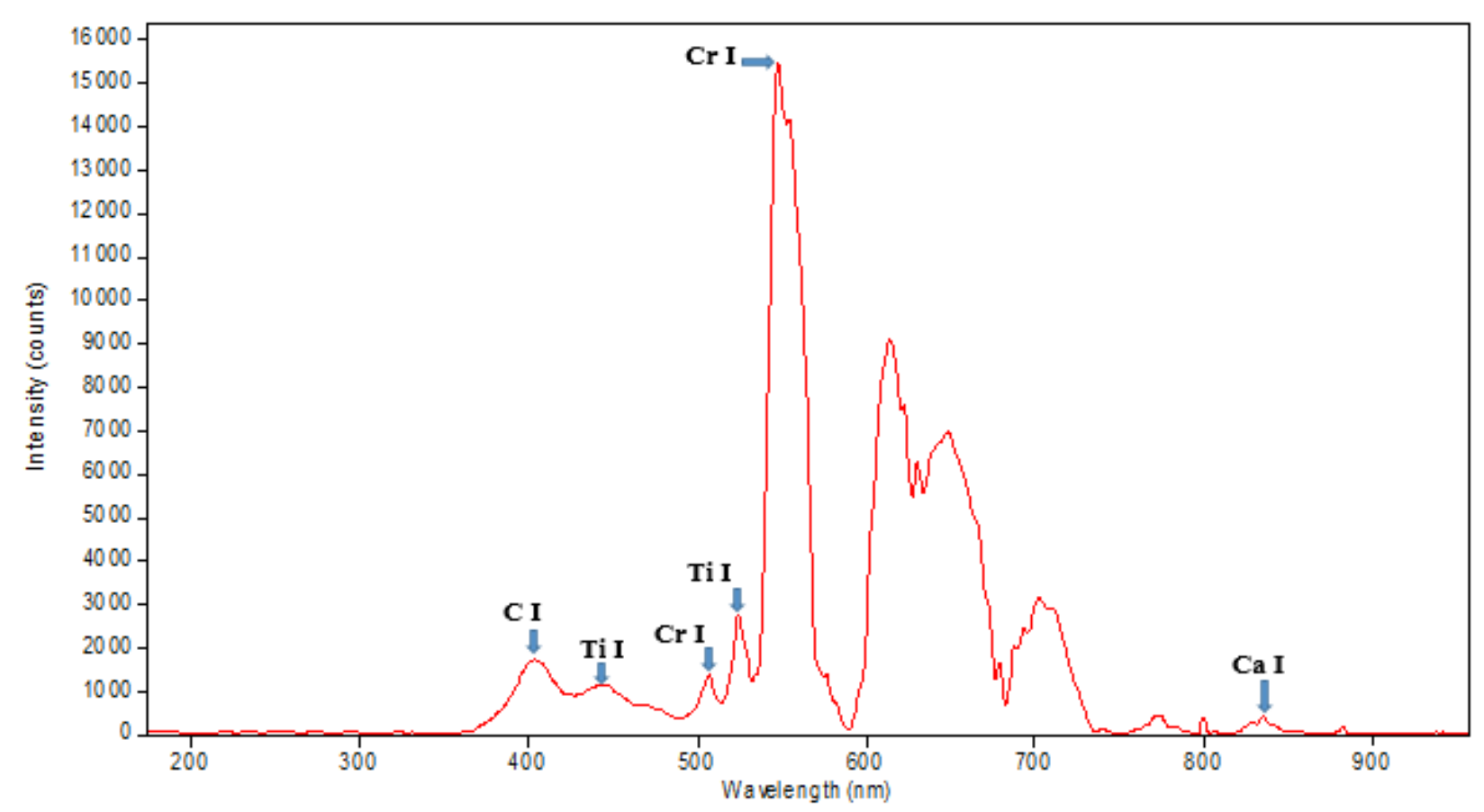

Figure 3. LIBS spectrum of the white office paper at $\left(2 \times 10^{12} \mathrm{~W} / \mathrm{cm}^{2}\right)$.

Table 3. List of the spectral emission lines for elements.

\begin{tabular}{|c|c|c|c|c|}
\hline No. & $\lambda($ LIBS)nm & I & Element & $\lambda$ (NIST)nm \\
\hline 1 & 403.160 & 1716.36 & C I & 403.179 \\
\hline 2 & 445.379 & 1146.45 & Ti I & 445.385 \\
\hline 3 & 506.754 & 1363.36 & Cr I & 506.771 \\
\hline 4 & 523.997 & 2723.82 & Ti I & 523.993 \\
\hline 5 & 548.106 & 15498.8 & Cr I & 548.101 \\
\hline 6 & 647.971 & 6969.55 & Ti I & 647.944 \\
\hline 7 & 835.251 & 397.545 & Ca I & 835.239 \\
\hline
\end{tabular}

With increasing the energy $(80 \mathrm{~mJ})$, which equates the power density to $\left(2.66 \times 10^{12} \mathrm{~W} / \mathrm{cm}^{2}\right)$. The spectrum analyzer recorded the new emissions spectral lines for Barium (Ba II) at $403.603 \mathrm{~nm}$, Praseodymium (Pr I) at $468.775 \mathrm{~nm}$, Titanium (Ti I) at $444.943 \mathrm{~nm}$ and $882.110 \mathrm{~nm}$, (Ti II) at $547.693 \mathrm{~nm}$, Manganese (Mn II) at 647.586 $\mathrm{nm}$ and Aluminum ( $\mathrm{Al} \mathrm{I}$ ) at $800.304 \mathrm{~nm}$, as shown in fig. (4). 


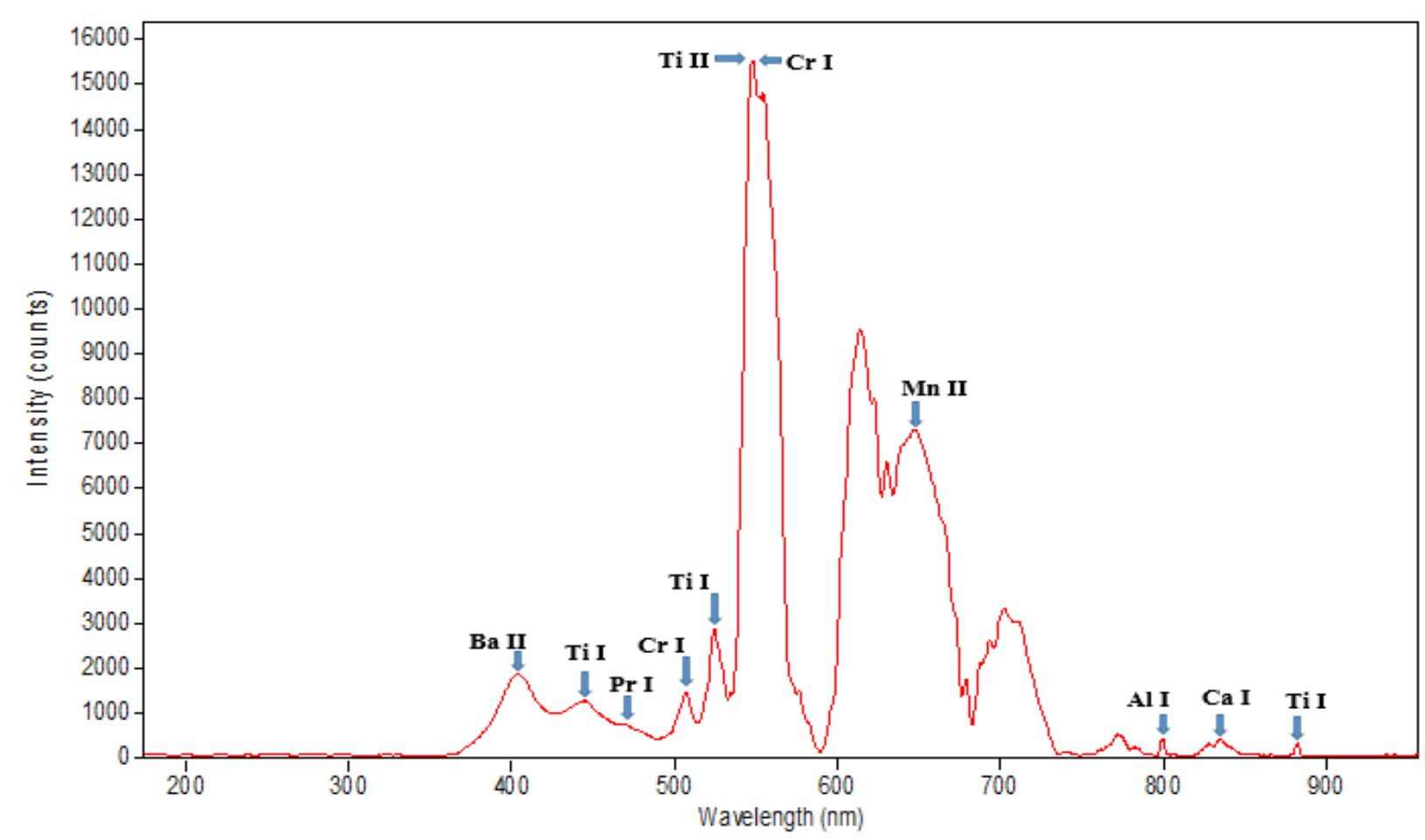

Figure 4. LIBS spectrum of the white office paper at $\left(2.66 \times 10^{12} \mathrm{~W} / \mathrm{cm}^{2}\right)$.

At laser energy $(100 \mathrm{~mJ})$, which equates $\left(3.33 \times 10^{12} \mathrm{~W} / \mathrm{cm}^{2}\right)$ power density, appearance the emission spectral lines unsuitable because of increasing the power density and hence become saturation in emission lines that lead to removing and lost in some emission lines, as shown in fig. (5). With increasing the power density will be lost most information in the sample.

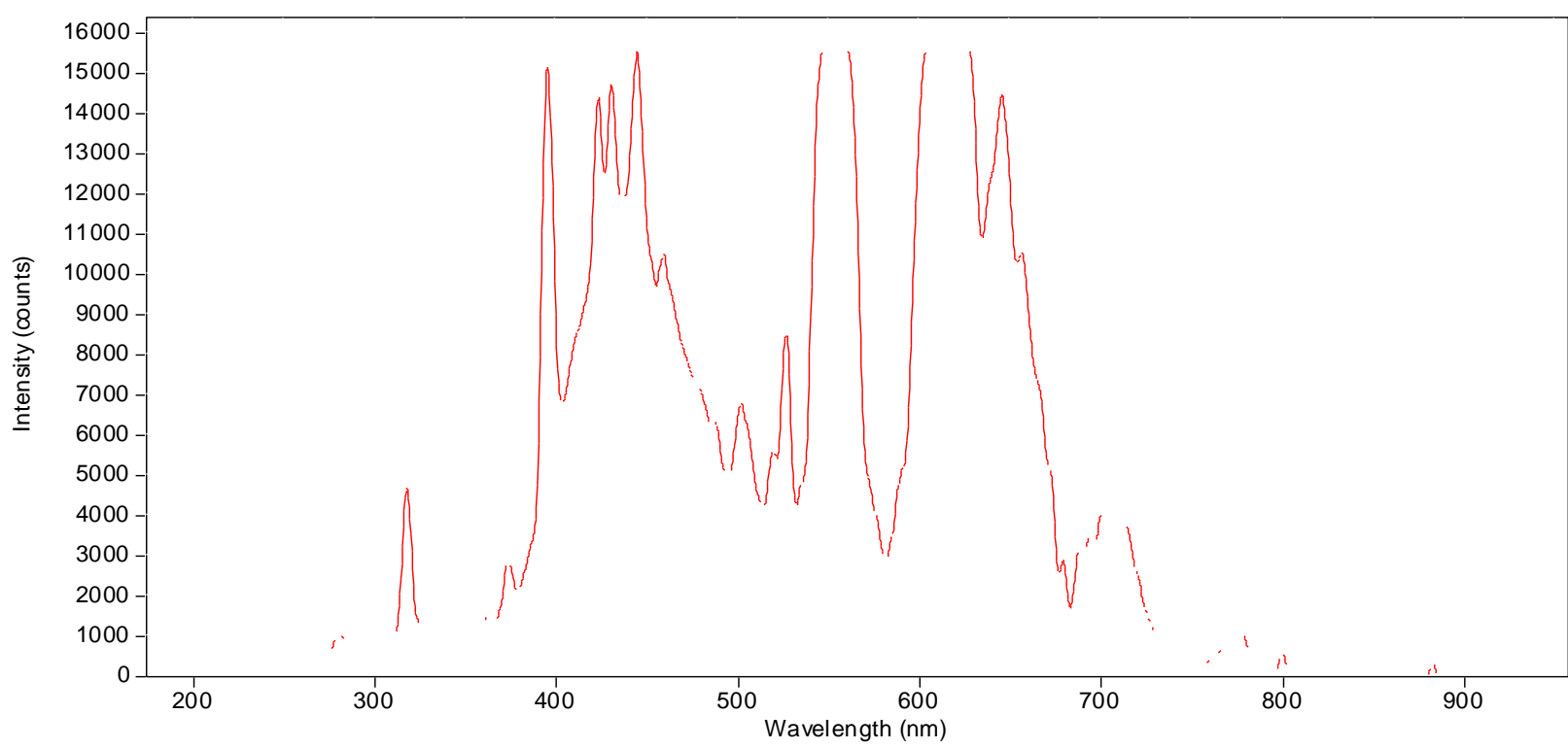

Figure 5 . LIBS spectrum of the white office paper at $\left(3.33 \times 10^{12} \mathrm{~W} / \mathrm{cm}^{2}\right)$.

\subsection{The ionization power density for inks}

The analysis of inks on paper is more difficult than the analysis of paper itself because inks are absorbed to some extent into the fibers of the paper and created a thin layer on the paper surface. the laser power density must be enough to ionization the inks without ablation the paper. With the different power density, will study the effect of laser shot on the emission spectrum of the generated plasma. an investigation was performed using a blue ballpoint pen sample (BB1).

By the optical spectrum analyzer recorded the emission spectrum lines as shown in fig. (6), at the laser energy $(60 \mathrm{~mJ})$, which equality the power density $\left(2 \times 10^{12} \mathrm{~W} / \mathrm{cm}^{2}\right)$. 


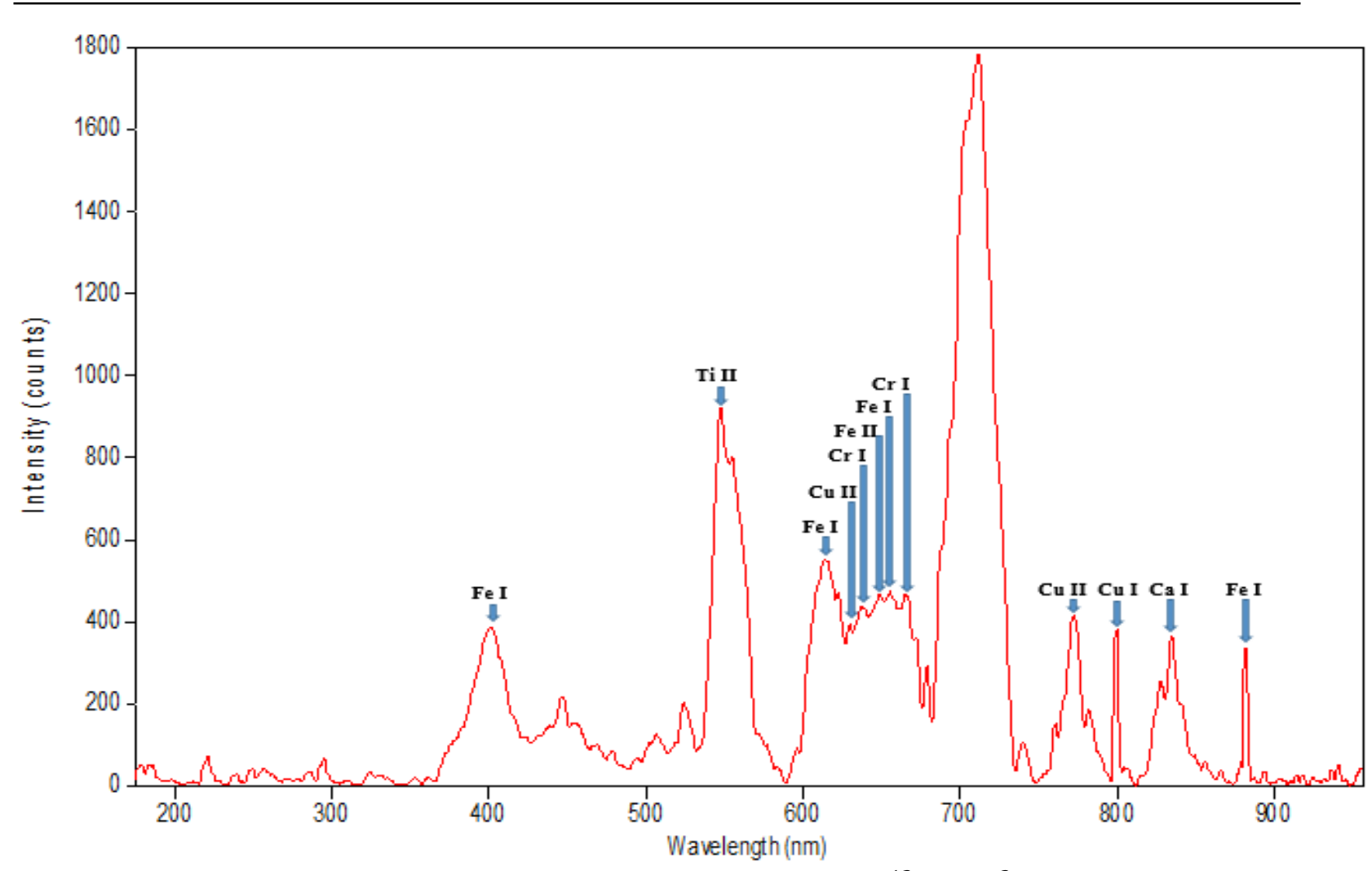

Figure 6. LIBS spectrum of the BB1 sample $\left(2 \times 10^{12} \mathrm{~W} / \mathrm{cm}^{2}\right)$.

The emission spectra of laser-induced breakdown observed in the spectral range (400-900) nm as illustrated in the table (4) below.

Table 4. List the spectral emission lines for elements BB1 sample at power density $\left(2 \times 10^{12} \mathrm{~W} / \mathrm{cm}^{2}\right)$.

\begin{tabular}{|c|c|c|c|c|}
\hline No. & $\lambda($ LIBS$) \mathrm{nm}$ & $\mathrm{I}$ & Element & $\lambda($ NIST)nm \\
\hline 1 & 401.384 & 386.364 & Fe I & 401.382 \\
\hline 2 & 547.693 & 918.909 & Ti II & 547.666 \\
\hline 3 & 613.599 & 550.455 & Fe I & 613.579 \\
\hline 4 & 613.994 & 550.455 & Fe I & 613.986 \\
\hline 5 & 630.113 & 393.455 & Cu II & 630.101 \\
\hline 6 & 637.519 & 437 & Cr I & 637.519 \\
\hline 7 & 649.127 & 466.091 & Fe II & 649.125 \\
\hline 8 & 655.659 & 471.545 & Fe I & 655.678 \\
\hline 9 & 665.204 & 464 & Cr I & 665.235 \\
\hline 10 & 772.674 & 416.091 & Cu II & 772.663 \\
\hline 11 & 800.635 & 383.636 & Cu I & 800.621 \\
\hline 12 & 835.251 & 362.818 & Ca I & 835.239 \\
\hline 13 & 882.403 & 335.455 & Fe I & 882.422 \\
\hline
\end{tabular}

When raising the amount of the laser energy to become $(80 \mathrm{~mJ})$, which equals the power density $(2.66 \times$ $10^{12} \mathrm{~W} / \mathrm{cm}^{2}$ ). Will appearance a new line with the shift of the center of some lines of the spectrum as shown in fig (7) below. 


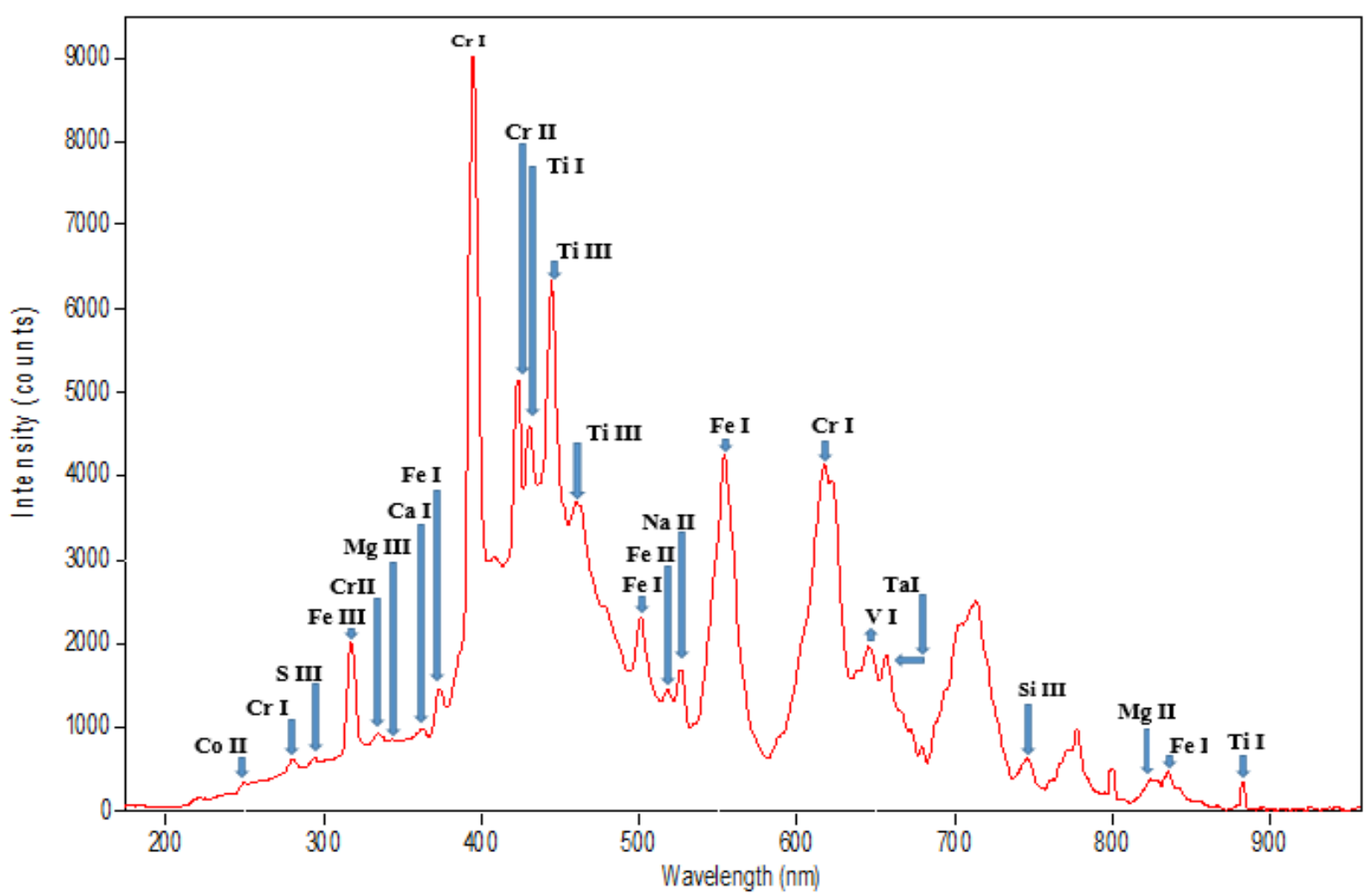

Figure 7. LIBS spectrum of the BB1 sample at $\left(2.66 \times 10^{12} \mathrm{~W} / \mathrm{cm}^{2}\right)$.

The resulted spectral emission lines in the range (200-900) nm, as illustrate in table (5).

Table 5. List the spectral emission lines for elements at $\left(2.66 \times 10^{12} \mathrm{~W} / \mathrm{cm}^{2}\right)$.

\begin{tabular}{|c|c|c|c|c|}
\hline No. & $\lambda($ LIBS$) n m$ & I & Element & Co II \\
\hline 1 & 249.757 & 336.909 & Cr I & 249.753 \\
\hline 2 & 280.519 & 614.818 & S III & 280.519 \\
\hline 3 & 294.869 & 635.818 & Fe III & 294.832 \\
\hline 4 & 317.415 & 2027.55 & Cr II & 317.409 \\
\hline 5 & 334.783 & 926 & Mg III & 334.783 \\
\hline 6 & 343.427 & 849 & Ca I & 343.423 \\
\hline 7 & 362.439 & 992.727 & Fe I & 362.411 \\
\hline 8 & 372.793 & 1442.91 & P III & 372.780 \\
\hline 9 & 394.712 & 9280.82 & Cr I & 394.712 \\
\hline 10 & 408.037 & 3029.45 & Ti I & 408.008 \\
\hline 11 & 423.047 & 5152.09 & Ti III & 423.047 \\
\hline 12 & 430.077 & 4601.18 & Ti III & 430.055 \\
\hline 13 & 444.072 & 6340.18 & Fe I & 444.065 \\
\hline 14 & 460.141 & 3690.82 & Fe II & 460.151 \\
\hline 15 & 500.829 & 2314.45 & Na II & 500.863 \\
\hline 16 & 517.707 & 1450 & Fe I & 517.701 \\
\hline 17 & 526.088 & 1695.45 & Cr I & 526.066 \\
\hline 18 & 553.874 & 4250.09 & V I & 553.851 \\
\hline 19 & 617.154 & 4141.82 & Ta I & 617.156 \\
\hline 20 & 645.269 & 1969.36 & Si III & 645.234 \\
\hline 21 & 656.426 & 1858.73 & Mg II & 656.426 \\
\hline 22 & 746.252 & 625.364 & Ti I & 746.262 \\
\hline 23 & 823.467 & 382.455 & & 823.463 \\
\hline 24 & 834.935 & 336.545 & & 834.904 \\
\hline 25 & 882.11 & & & \\
\hline
\end{tabular}

From Fig. (8), it is clear that when increase the laser energy to become $(100 \mathrm{~mJ})$, which equals the laser power density $\left(3.33 \times 10^{12} \mathrm{~W} / \mathrm{cm}^{2}\right)$, has a strong and important effect on the emission line intensities, where the 
intensities of the spectral lines increase with increase in the laser power density because of the increasing the mass ablation rate, which leads to increasing the number of excited atoms and hence the peaks of spectral line intensities, and occur saturation as shown in the spectral emission lines (547.693 for Ti I ), ( 548.106, 548.518 for Cr I), and (554.286 for V I) of the figure (8) below. Also, the highest laser power density caused of the strong effect paper spectrum and appearance a new spectral emission lines is (547.693 for Ti, 548.106 for $\mathrm{Cr} \mathrm{I}$, 800.304 for Al I and 835.251 for Ca I) for elements paper spectrum. The all resulted from spectral emission lines in spectrum range $(200-900 \mathrm{~nm})$ due to the increase the power density is illustrated in the table (6).

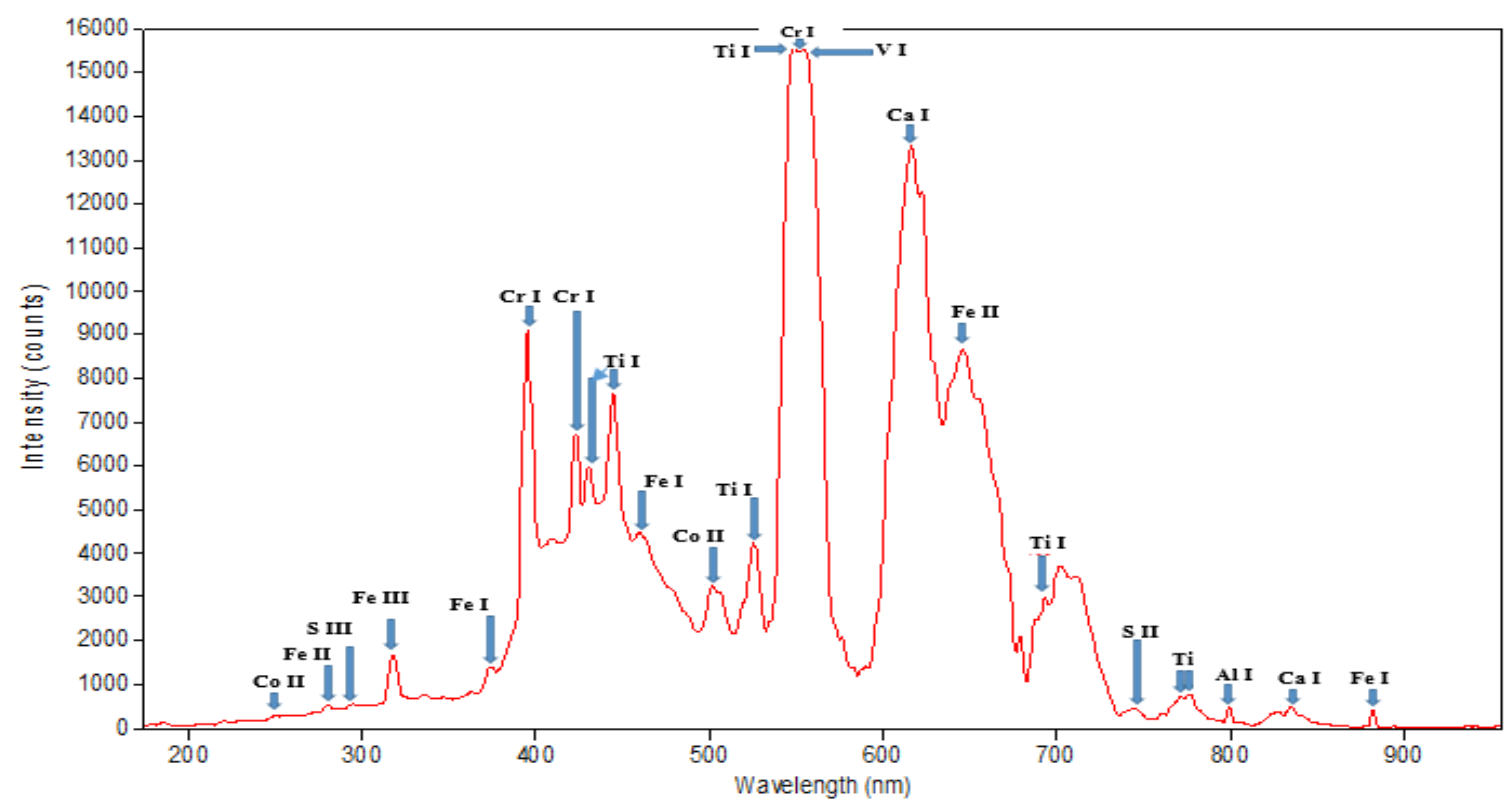

Figure 8.LIBS spectrum of the BB1 sample at $\left(3.33 \times 10^{12} \mathrm{~W} / \mathrm{cm}^{2}\right)$.

Table 6. List for all the spectral emission lines for elements at $\left(3.33 \times 10^{12} \mathrm{~W} / \mathrm{cm}^{2}\right)$.

\begin{tabular}{|c|c|c|c|c|}
\hline No. & $\lambda($ LIBS) & I & Element & $\lambda($ NIST ) \\
\hline 1 & 249.757 & 293.091 & Co II & 249.753 \\
\hline 2 & 280.055 & 506.455 & Fe II & 280.053 \\
\hline 3 & 294.869 & 534.727 & S III & 317.409 \\
\hline 4 & 317.415 & 1690.45 & Fe III & 374.5899 \\
\hline 5 & 374.589 & 1386.45 & Fe I & 394.712 \\
\hline 6 & 394.712 & 9118.91 & Cr I & 409.802 \\
\hline 7 & 409.808 & 4321.82 & Cr I & 423.0471 \\
\hline 8 & 423.047 & 6748.09 & Cr I & 430.055 \\
\hline 9 & 430.077 & 5967.27 & Ti I & 444.0657 \\
\hline 10 & 444.072 & 7652 & Ti III & 459.2651 \\
\hline 11 & 459.275 & 4472.36 & Fe I & 501.6846 \\
\hline 12 & 501.677 & 3257.18 & Co II & 524.8386 \\
\hline 13 & 524.834 & 4246.36 & Ti I & 547.666 \\
\hline 14 & 547.693 & 15547 & Ti I & 548.101 \\
\hline 15 & 548.106 & 15547 & Cr I & 548.519 \\
\hline 16 & 548.518 & 15547 & Cr I & 554.2716 \\
\hline 17 & 554.286 & 15543.5 & V I & 616.376 \\
\hline 18 & 616.365 & 13333 & Ca I & 645.6381 \\
\hline 19 & 645.656 & 8672.82 & Fe II & 693.3139 \\
\hline 20 & 693.388 & 2981.27 & Ti I & 744.4609 \\
\hline 21 & 744.486 & 442.091 & S II & 771.6909 \\
\hline 22 & 771.646 & 769.636 & Ti II & 776.7439 \\
\hline 23 & 776.775 & 466.364 & Al I & 800.3186 \\
\hline 24 & 800.304 & 406.727 & Fa I I & 835.239 \\
\hline 25 & 835.251 & & & \\
\hline 26 & 882.403 & & 4221 \\
\hline
\end{tabular}


Generally, the increase of the laser power density greater than $\left(3.33 \times 10^{12} \mathrm{~W} / \mathrm{cm}^{2}\right)$ for a generation of plasma in the BB1, BK2, and GB3 samples, the intensity of the emission lines of spectral will be increased respectively and hence showed over peak unreadable of spectra as shown in fig. (9) and (10), when increase the lasers energies to $(300 \mathrm{~mJ}$ and $500 \mathrm{~mJ})$, which equals the power densities $\left(10 \times 10^{12} \mathrm{~W} / \mathrm{cm}^{2}\right)$ and $\left(16.66 \times 10^{912} \mathrm{~W} / \mathrm{cm}^{2}\right)$ for the samples BK2 and GB3 respectively.

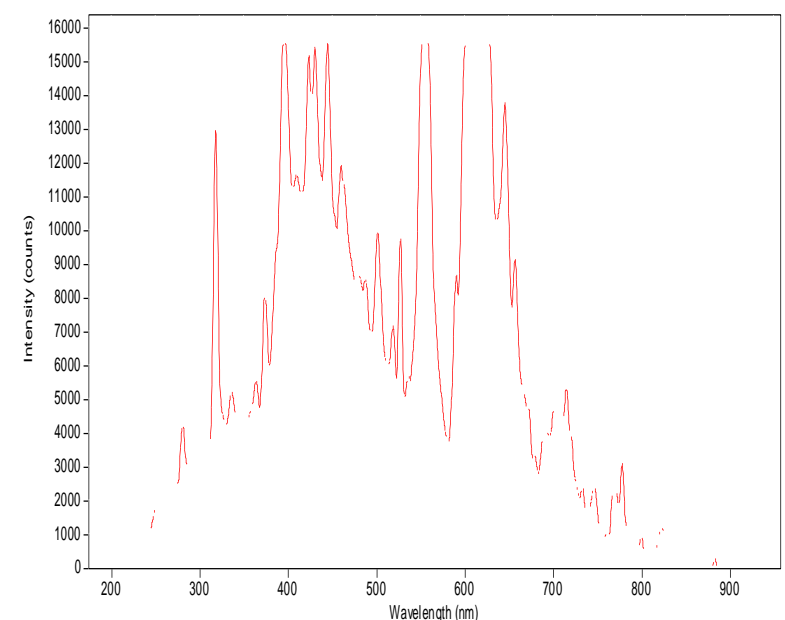

Figure 9. LIBS spectrum of the BK2 sample.

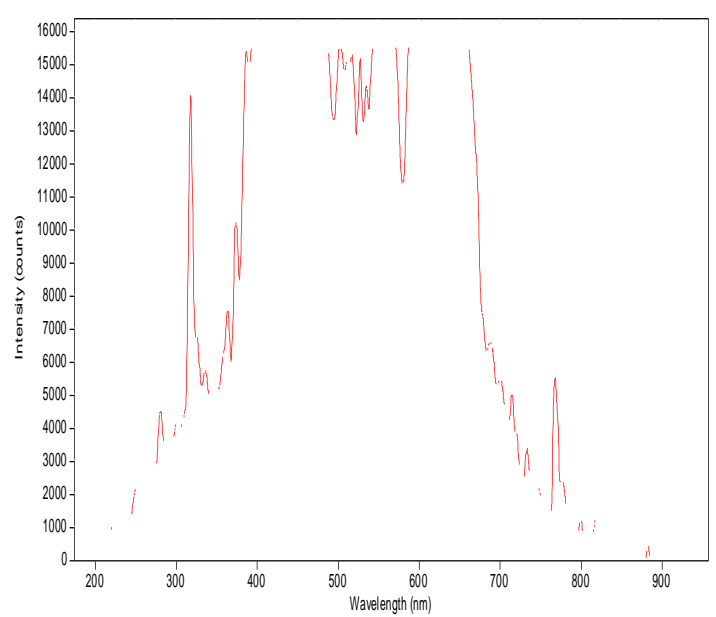

Figure 10. LIBS spectrum of the GB3 sample.

This can have interpreted as follows:

The increase of laser power density leads to increase in mass ablation rate from the target, means more excited atoms and hence increasing in the height of the spectral line intensities. Whilst, the low energy of laser less than $(60 \mathrm{~mJ})$ did not demonstrate a peak of elemental spectra, because the intensity of the spectral lines decrease with the decreasing in the laser power density, the decrease of laser power density leads to decrease in mass ablation rate from the target, means less excited atoms and hence decreasing in the height of the spectral line intensities.

\section{Conclusions}

LIBS is low cost and high-efficiency system to analyze the writing inks compared to all other technologies of analysis. show the results that the laser energy $(80 \mathrm{~mJ})$, which equals the power density $(2.66 \times$ $10^{12} \mathrm{~W} / \mathrm{cm}^{2}$, was the best power to generate plasma homogeneous for all component writing inks and ionize it without effect on the paper material. Where, show the results at this energy the main emission lines for ink material, which was from the elements $(\mathrm{Cr}, \mathrm{Fe}, \mathrm{Na}, \mathrm{Ti}, \mathrm{Ca}, \mathrm{Ta}, \mathrm{Si})$ for ballpoint pens inks and ( $\mathrm{V}, \mathrm{Na}, \mathrm{Cr}, \mathrm{Ti}$, $\mathrm{S}, \mathrm{W}, \mathrm{Ca})$ for gel pen ink.

When the laser energy $(60 \mathrm{~mJ})$, which equals $\left(2 \times 10^{12} \mathrm{~W} / \mathrm{cm}^{2}\right)$ laser power density, the plasma spectra was contain on the some component of ink material, because the ionization process of inks materials and converted to plasma was did not enough to occur the full ionization. Where, show the main emission lines for some component of ink material and did not show the emission lines for other elements.

With raising the amount laser energy become $(100 \mathrm{~mJ})$ that equal to $\left(3.33 \times 10^{12} \mathrm{~W} / \mathrm{cm}^{2}\right)$ power density, was very high and caused ionization both ink and paper material. Where, showed the emission lines spectral main for inks and emission lines spectral for paper.

Consequently, the increasing the energy to $(200 \mathrm{~mJ}, 300 \mathrm{~mJ}, 400 \mathrm{~mJ}, 500 \mathrm{~mJ})$, the intensity of the power density will become very high, and lead to show emission lines spectral for paper matter. where, there is the elements inside in manufacture both inks and paper, thus, these energies lead to occur overlap in emissions and occur an error in results. Increase the energy limit $500 \mathrm{~mJ}$, lead to damage to the sample. thus, this energy is unsuitable for using forensic.

\section{Reference}

Bass, M. (1994). Chapter 24. Radiometry and photometry.

El-Deftar, M. M. A. (2014). Evaluation of Laser-Induced Breakdown Spectroscopy (LIBS) for the Elemental Profiling of Forensic Evidence (Doctoral dissertation, University of Canberra).

Häkkänen, H. J., \& Korppi-Tommola, J. E. (1998). Laser-induced plasma emission spectrometric study of pigments and binders in paper coatings: matrix effects. Analytical Chemistry, 70(22), 4724-4729. 
Hoehse, M., Paul, A., Gornushkin, I., \& Panne, U. (2012). Multivariate classification of pigments and inks using combined Raman spectroscopy and LIBS. Analytical and bioanalytical chemistry, 402(4), 1443-1450.

Karamida, A. Ralchenko, Yu., Reader, J, and NIST ASD Team (2018), NIST atomic spectra database (Ver. 5.5.2), [online], National institute of standards and technology, Gaithersburg, MD.

Kula, A., Wietecha-Posłuszny, R., Pasionek, K., Król, M., Woźniakiewicz, M., \& Kościelniak, P. (2014).

Application of laser induced breakdown spectroscopy to examination of writing inks for forensic purposes. Science \& Justice, 54(2), 118-125.

Mateo, M. P., Ctvrtnickova, T., \& Nicolas, G. (2009). Characterization of pigments used in painting by means of laser-induced plasma and attenuated total reflectance FTIR spectroscopy. Applied Surface Science, 255(10), 5172-5176.

Melessanaki, K., Papadakis, V., Balas, C., \& Anglos, D. (2001). Laser induced breakdown spectroscopy and hyper-spectral imaging analysis of pigments on an illuminated manuscript. Spectrochimica Acta Part B: Atomic Spectroscopy, 56(12), 2337-2346.

Miziolek, A. W., Palleschi, V., \& Schechter, I. (Eds.). (2006). Laser induced breakdown spectroscopy. Cambridge university press.

Oujja, M., Vila, A., Rebollar, E., García, J. F., \& Castillejo, M. (2005). Identification of inks and structural characterization of contemporary artistic prints by laser-induced breakdown spectroscopy. Spectrochimica Acta Part B: Atomic Spectroscopy, 60(7-8), 1140-1148.

Ponterio, R., Trusso, S., Vasi, C., La Torre, G. F., \& Toscano Raffa, A. (2008). Laser induced breakdown spectroscopy for the analysis of archaeological dyes from Licata (Sicily). Radiation Effects \& Defects in Solids, 163(4-6), 535-543.

Sansonetti, J. E., \& Martin, W. C. (2005). Handbook of basic atomic spectroscopic data. Journal of Physical and Chemical Reference Data, 34(4), 1559-2259.

Silfvast, W. T. (2004). Laser fundamentals. Cambridge university press.

Trejos, T., Flores, A., \& Almirall, J. R. (2010). Micro-spectrochemical analysis of document paper and gel inks by laser ablation inductively coupled plasma mass spectrometry and laser induced breakdown spectroscopy. Spectrochimica Acta Part B: Atomic Spectroscopy, 65(11), 884-895. 